\title{
Efficacy of Buspirone Augmentation of Escitalopram in Patients with Major Depressive Disorder with and without Atypical Features: A Randomized, 8 Week, Multicenter, Open-Label Clinical Trial
}

\author{
Cheolmin Shin', Young-Hoon Ko', Se-Hoon Shim², Ji Sun Kim², \\ Kyoung-Sae $\mathrm{Na}^{3}$, Sang-Woo Hahn ${ }^{4}$, and Seung-Hwan Lee ${ }^{5,6}$ \\ ${ }^{1}$ Department of Psychiatry, Korea University College of Medicine, Korea University Ansan Hospital, Ansan, Republic of Korea \\ ${ }^{2}$ Department of Psychiatry, Soonchunhyang University College of Medicine, Soonchunhyang University Cheonan Hospital, Cheonan, Republic of Korea \\ ${ }^{3}$ Department of Psychiatry, Gachon University College of Medicine, Gil Medical Center, Incheon, Republic of Korea \\ ${ }^{4}$ Department of Psychiatry, Soonchunhyang University College of Medicine, Soonchunhyang University Hospital, Seoul, Republic of Korea \\ ${ }^{5}$ Department of Psychiatry, Inje University Ilsan Paik Hospital, Goyang, Republic of Korea \\ ${ }^{6}$ Clinical Emotion and Cognition Research Laboratory, Inje University Ilsan Paik Hospital, Goyang, Republic of Korea
}

Objective This study investigated the treatment response and cognitive enhancement effects of buspirone augmentation of escitalopram in patients with major depressive disorder (MDD), according to atypical feature subtypes of MDD.

Methods An 8 week, randomized, parallel-controlled, open-label study was conducted. The Columbia Atypical Depression Diagnostic Scale was administered to evaluate atypical features. Patients were assigned randomly to the buspirone augmentation or non-buspirone groups. Symptom severity and cognitive function were evaluated using the 17-item Hamilton Depression Rating Scale, Hamilton Anxiety Rating Scale, Beck Depression Inventory, Beck Anxiety Inventory, digit span test, word fluency test, and Trail Making Tests A and B.

Results A total of 89 patients were recruited. There were no significant differences in the measures between the groups; however, among the MDD patients without atypical features, the digit span and word fluency tests were improved by treatment. In the MDD patients without atypical features, the buspirone augmentation group showed a significant improvement on the digit span test compared to the non-buspirone group.

Conclusion Buspirone augmentation did not demonstrate significant benefits in MDD patients; however, buspirone augmentation showed greater efficacy for the improvement of cognitive function in MDD patients without atypical features. Our study suggests that atypical features are an important factor for cognitive enhancement in buspirone augmentation treatment in patients with MDD.

Psychiatry Investig 2020;17(8):796-803

Key Words Atypical features, Major depressive disorder, Digit span, Buspirone, Escitalopram.

\section{INTRODUCTION}

Major depressive disorder (MDD) is a common psychiatric illness leading to morbidity and severe functional and cognitive impairments. ${ }^{1-3}$ Monotherapeutic antidepressants are an effective treatment for MDD; however, they often demonstrate insufficient therapeutic efficacy. In addition, MDD is accom-

\footnotetext{
Received: January 15, 2020 Revised: April 28, 2020 Accepted: June 2, 2020

$\triangle$ Correspondence: Seung-Hwan Lee, MD, PhD

Department of Psychiatry, Inje University Ilsan Paik Hospital, 170 Juhwa-ro, Ilsanseo-gu, Goyang 10380, Republic of Korea

Tel: +82-31-910-7776, Fax: +82-31-919-9776, E-mail: 1shpss@hanmail.net

@ This is an Open Access article distributed under the terms of the Creative Commons Attribution Non-Commercial License (https://creativecommons.org/licenses/bync/4.0) which permits unrestricted non-commercial use, distribution, and reproduction in any medium, provided the original work is properly cited.
}

panied by anxiety, cognitive dysfunction, somatic symptoms, and other clinically relevant symptoms. ${ }^{5}$ Therefore, treatment strategies of augmentation or combination therapies with other pharmacotherapeutic agents are often recommended.

Buspirone, a serotonin (5-HT) 1A receptor agonist (full agonist for the presynaptic 5-HT1A receptors, which are inhibitory autoreceptors, and partial agonist for the postsynaptic 5-HT1A receptors, result in increased 5-HT1A receptors functioning) and presynaptic inhibitory D2 autoreceptor antagonist at dopaminergic neuron, was first approved as an anxiolytic for the treatment of generalized anxiety disorder by the United States Food and Drug Administration. ${ }^{67}$ Buspirone has also been shown to be effective in treating anxiety symptoms associated with MDD. ${ }^{8}$ Moreover, buspirone has been found to be potentially useful for its antidepressant effects by 
enhancing 5-HT neuronal activity. ${ }^{9}$ When buspirone binds to the somatodendritic 5-HT1A receptors present in serotonergic neurons of the raphe nuclei, the neuronal impulse temporarily decreases. Once this phase elapses and depleted serotonin increases around the dendrite, this results in the downregulation of the 5-HT1A autoreceptor of raphe neurons and the increase in postsynaptic 5-HT1A neuronal impulses in projection areas. ${ }^{10}$ Consequently, there is an overall increase in serononergic neurotransmission.

Previously, pre- and postsynaptic 5-HT1A agonists in the medial septum have been found to improve cognitive function in preclinical studies, which is thought to be due to the role of the 5-HT1A receptor as an accelerator of dopamine in the frontal cortex and choline in the hippocampus. ${ }^{11-13}$ Typically, when serotonin binds to the somatodendritic 5-HT1A receptors present in serotonergic neurons, the secretion of serotonin decreases at the end stage, leading to the decreased the secretion of gamma-aminobutyric acid (GABA) from GABAergic interneurons and disinhibition of the inhibition of dopaminergic neurons. Through this process, the activity of dopaminergic neurons returns to baseline. In a preclinical study, a low dose of buspirone preferentially stimulates somatodendritic 5-HT1A receptors in the raphe neuclei, resulting in a decrease in striatal serotonin metabolism and releases dopaminergic neurons from the inhibitory influence of serotonin, which may be useful in reducing Parkinsonian-like effects of traditional antipsychotics and improving cognitive functions. ${ }^{14}$; however, in clinical studies, cognitive functional improvements with 5-HTA1 agonists are scarcely reported, except using tandospirone in schizophrenia patients to induce cognitive improvements. ${ }^{15,16}$

There is accumulating evidence that the clinical manifestation, biological characteristics, and drug treatment response differ according to the presence or absence of atypical features in MDD patients. ${ }^{17,18} \mathrm{MDD}$ without atypical features is related to biological abnormalities including dysregulation of the hypothalamic-pituitary-adrenal (HPA) axis, ${ }^{19,20}$ functional and structural neuroanatomical abnormalities ${ }^{21,22}$ and is more clinically related to cognitive dysfunction. ${ }^{23}$ In terms of treatment, atypical MDD demonstrates a different response to biological therapies, such as pharmacotherapy and electroconvulsive therapy, compared to MDD without atypical features. ${ }^{18,24}$

The present study aimed to evaluate treatment response between the monotherapeutic approach, using a selective serotonin reuptake inhibitor (SSRI), and augmentation therapy, using an SSRI and buspirone. In addition, we investigated whether buspirone as an adjunct treatment is effective in improving clinical and cognitive function based subtypes of MDD with or without atypical features.

\section{METHODS}

\section{Participants}

Male and female outpatients (20-65 years) who met the Diagnostic and Statistical Manual of Mental Disorders, 5th edition (DSM-5) criteria for MDD (based on diagnosis by board-certified psychiatrists) were eligible for inclusion. At screening and baseline, patients were administered the 17item Hamilton Depression Rating Score $\left(H A M-D_{17}\right)$, where they were required to have a score of at least 18 and to have remained drug naïve at least for the last 8 weeks. ${ }^{25}$

The exclusion criteria of this study were patients demonstrating: any concurrent medical condition in their medical history, coexisting major psychiatric illness (i.e., meeting DSM5 criteria for any manic or hypomanic episode, schizophrenia obsessive compulsive, psychotic, alcohol use disorder, and dementia and any other cognitive disorder), personality disorders, the risk of injuring others or self, and suicide risk (i.e., attempt within the past year). Blood chemistry, such as thyroid function test, complete blood count, and aspartate aminotransferase/alanine transaminase, was evaluated and screened for any abnormal findings. Patients were asked to have not taken antipsychotics, anticonvulsants, mood stabilizers, anxiolytics, sedative/hypnotics, or antidepressants for at least 8 weeks before baseline. Those who underwent of undergoing electroconvulsive therapy, repetitive transcranial magnetic stimulation, or transcranial direct current stimulation therapy within the last 6 months, or who had inadequate responses to central nervous system treatment in the past were excluded.

\section{Trial design}

The present study was conducted as a multicenter, randomized, open label, and observational study at seven sites. All Institutional Review Boards (IRB) approved the study protocol and any required amendments (Inje University Ilsan Paik Hospital: IRB-2015-04-316-019; Soon Chun Hyang University Cheonan Hospital: IRB-2015-09-008; Korea University Ansan Hospital: IRB-2015AS0098; Gachon University Gil Medical Center: IRB-GBIRB2015-349; SoonChunHyang Seoul Hospital: IRB-SCHUH2015-10-034). The present study was conducted in accordance with the Declaration of Helsinki and was consistent with Good Clinical Practices and applicable regulatory requirements. All individuals provided written informed consent after thorough explanation of trial procedure and potential risks prior to participation.

Patients were randomly assigned to escitalopram plus buspirone augmentation group or non-buspirone group. In the present study, the dose of escitalopram started at $5 \mathrm{mg}$ and was titrated to a maximum of $20 \mathrm{mg}$. The starting dose of 
buspirone was $5 \mathrm{mg}$ twice per day and titrated to a total of 60 mg per day (the maximum dose based on the Korea Food and Drug Administration), and the dosage was maintained at 30-60 mg per day until the end of the study. For the control of insomnia and acute anxiety, patients were permitted up to $2 \mathrm{mg}$ of lorazepam and $1 \mathrm{mg}$ of alprazolam. Only conventional, short-term, supportive psychotherapy was allowed.

\section{Efficacy measures}

\section{Psychological assessments}

The Columbia Atypical Depression Diagnostic Scale (ADDS) was administered to determine the presence of atypical subtype ${ }^{26}$ Symptom severity was measured using the HAM- $\mathrm{D}_{17}$, Hamilton Anxiety Rating Scale (HAM-A), ${ }^{27}$ Beck Depression Inventory (BDI) ${ }^{28}$ Beck Anxiety Inventory (BAI), ${ }^{29}$ Clinical Global Impression-Severity (CGI-S), ${ }^{30}$ and Ruminative Response Scale (RRS). ${ }^{31}$ Assessments of HAM-D ${ }_{17}$, HAM-A, BDI, BAI, CGI-S, and RRS were conducted at each visit (baseline and weeks 2,4 , and 8 ).

\section{Cognitive function assessments}

Cognitive function was measured at baseline (week 0 ) and week 8 using the digit span, verbal fluency, and trail making tests (TMT). The digit span test consists of the forward and backward digit span tests. ${ }^{32}$ The forward digit span test begins with a three digit number, where one number is dictated every second, and the participant is asked to repeat the three digits. If the participant passes, four digit numbers are tested, and can be conducted up to nine digits. The backward digit span test starts with a two digit number, where one number is dictated every second, and the participant is asked to repeat the two digits in reverse order. Like the forward digit span test, more digit numbers are asked, if a participant successfully repeats (up to six digit). Total digit span score is the sum of number of forward and backward digit span. Therefore, the larger digit span score indicate the better performance of the test. The word fluency test examines the ability of patients to retrieve words of a certain semantic category under time limits. ${ }^{33}$ This test is performed by the participant listing as many animals or types of items to be purchased at the market within $1 \mathrm{~min}$. More words produced in this test indicate a better cognitive function. Finally, the TMT is divided into two parts. ${ }^{34}$ Type A (TMT-A) requires participants to discern irregularly arranged numbers on the ground in order and connect them by lines, and Type B (TMT-B) asks them to alternate connecting numbers and letters in order. TMT-A and TMT-B are expressed as total completion time, and a smaller time means better performance of test.

\section{Statistical analyses}

To verify the baseline homogeneity between buspirone augmentation and non-buspirone groups, categorical variables (e.g., sex and education) were analyzed by $\chi^{2}$ test, and continuous variables (e.g., age and rating scales) were analyzed using independent $\mathrm{t}$ - or Mann-Whitney $\mathrm{U}$ tests if the assumption of normality was violated. The use of benzodiazepines during the trial was compared between the two groups by $\chi^{2}$ test.

The primary endpoint for all efficacy measures was the final on therapy evaluation using the last-observation-carriedforward method to account for missing data. ${ }^{35}$ Comparisons for all clinical scales, including HAM- $\mathrm{D}_{17}$, HAM-A, BDI, BAI, CGI-S, and RRS, between buspirone augmentation and nonbuspirone groups were performed using two-way repeated measures analysis of variance (ANOVA), with time (baseline and weeks 2,4 , and 8 ) as the within-subject factor and treatment (buspirone augmentation versus non-buspirone) and atypicality (with atypicality versus without atypicality) as between-subject factors. These analyses were followed by Bonferonni post-hoc tests for multiple comparisons.

An independent t-test was conducted to determine changes in cognitive function tests from baseline to endpoint between buspirone augmentation and non-buspirone groups, followed by a paired t-test to explore the results based on the presence of atypical features.

The above statistical analyses were performed using SPSS (version 20.0; IBM Corp., Armonk, NY, USA). All tests were considered statistically significant if the two-sided $\mathrm{p}$ value was less than 0.05 .

\section{RESULTS}

\section{Sociodemographic and clinical characteristics of participants}

Participants ( $\mathrm{n}=89)$ at baseline included 23 men (25.8\%) who were a mean age 42.61 years old [standard deviation $(\mathrm{SD})=$ 13.47], had a mean of 12.56 years of education $(\mathrm{SD}=2.48)$, and 18 individuals who smoked in the last 2 years (20.2\%). At baseline, there were no statistically significant differences in demographic variables, rating scales, and cognitive function tests except word fluency test between buspirone augmentation and non-buspirone groups (Table 1). MDD patients with or without atypical features were distinguished at baseline, and differences in sociodemographic and clinical characteristics between the two groups are presented in Table 2. The prevalence of use of benzodiazepine was $56.5 \%$ and $60.5 \%$ in the buspirone augmentation and non-buspirone groups, respectively, and there was no significant difference between the two groups. In the subgroup with atypical features and the 
subgroup without atypical features, there were also no significant differences between the two treatment groups in the use of benzodiazepine.

\section{Symptomatic changes}

Primary outcomes, including the HAM- $\mathrm{D}_{17}$, showed improvement on clinical rating scales in both the buspirone augmentation and non-buspirone groups (from 24.02 to 15.88 versus from 23.26 to 12.74 , respectively); however, there were

Table 1. Baseline demographic and clinical variables

\begin{tabular}{|c|c|c|c|c|}
\hline Variables & Buspirone augmentation $(\mathrm{N}=46)$ & Non-buspirone $(\mathrm{N}=43)$ & Statistics & $\mathrm{p}$ \\
\hline \multicolumn{5}{|l|}{ Sex } \\
\hline Male & $13(28.26)$ & $10(23.26)$ & \multirow{2}{*}{$0.291^{*}$} & \multirow{2}{*}{0.590} \\
\hline Female & $33(71.74)$ & $33(76.74)$ & & \\
\hline Age & $44.59(13.03)$ & $40.19(13.70)$ & $-1.55^{\dagger}$ & 0.124 \\
\hline Education & $12.24(2.69)$ & $12.90(2.21)$ & $1.25^{\dagger}$ & 0.216 \\
\hline \multicolumn{2}{|l|}{ Smoking (last 2 years) } & & $0.012^{*}$ & 0.914 \\
\hline Yes & $9(20.0)$ & $9(20.9)$ & & \\
\hline No & $36(80.0)$ & $34(79.1)$ & & \\
\hline Digit span & $15.78(4.38)$ & $17.05(4.21)$ & $1.38^{\dagger}$ & 0.170 \\
\hline Word fluency & $15.67(3.50)$ & $19.23(7.25)$ & $2.92^{\dagger}$ & $0.005^{\ddagger}$ \\
\hline Trail making test $\mathrm{A}$ & $48.77(36.13)$ & $42.74(25.22)$ & $-0.90^{\dagger}$ & 0.372 \\
\hline Trail making test B & $121.40(81.91)$ & $110.00(81.93)$ & $-0.59^{\dagger}$ & 0.554 \\
\hline Hamilton Depression Rating Scale & $24.02(5.86)$ & $23.67(6.11)$ & $-0.27^{\dagger}$ & 0.789 \\
\hline Hamilton Anxiety Rating Scale & $23.20(7.34)$ & $21.77(8.09)$ & $-0.85^{\dagger}$ & 0.400 \\
\hline Beck Depression Inventory & $31.50(11.91)$ & $28.98(10.42)$ & $-1.06^{\dagger}$ & 0.292 \\
\hline Beck Anxiety Inventory & $27.54(13.29)$ & $26.44(14.39)$ & $-0.38^{\dagger}$ & 0.708 \\
\hline Rumination Response Scale & $53.22(14.46)$ & $55.91(16.50)$ & $-0.90^{\dagger}$ & 0.925 \\
\hline
\end{tabular}

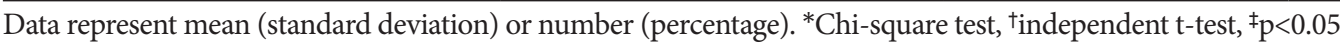

Table 2. Comparison of baseline demographic and clinical variables between patients with atypical features and without atypical features

\begin{tabular}{|c|c|c|c|c|}
\hline Variables & Atypical $(\mathrm{N}=42)$ & Non-atypical (N=46) & Statistics & $\mathrm{p}$ \\
\hline \multicolumn{5}{|l|}{ Sex } \\
\hline Male & $12(28.57)$ & $10(23.26)$ & \multirow{2}{*}{$0.247^{*}$} & \multirow{2}{*}{0.619} \\
\hline Female & $30(71.43)$ & $33(76.74)$ & & \\
\hline Age & $41.79(13.84)$ & $40.19(13.70)$ & $0.47^{\dagger}$ & 0.639 \\
\hline Education & $12.68(2.50)$ & $12.90(2.21)$ & $-0.42^{\dagger}$ & 0.673 \\
\hline \multicolumn{2}{|l|}{ Smoking (last 2 years) } & & $0.020^{*}$ & $0.033^{\ddagger}$ \\
\hline Yes & $13(31.0)$ & $5(10.9)$ & & \\
\hline No & $29(69.0)$ & $41(89.1)$ & & \\
\hline Digit span & $17.30(4.44)$ & $15.58(4.09)$ & $-1.90^{\dagger}$ & 0.061 \\
\hline Word fluency & $17.48(6.71)$ & $17.41(5.11)$ & $-0.05^{\dagger}$ & 0.960 \\
\hline Trail making test A & $41.13(21.80)$ & $50.60(37.42)$ & $1.41^{\dagger}$ & 0.163 \\
\hline Trail making test B & $115.67(75.61)$ & $116.83(88.73)$ & $0.06^{\dagger}$ & 0.952 \\
\hline Hamilton Depression Rating Scale & $25.46(6.80)$ & $22.34(4.63)$ & $-2.46^{\dagger}$ & $0.017^{\ddagger}$ \\
\hline Hamilton Anxiety Rating Scale & $25.44(7.07))$ & $19.63(7.29)$ & $-3.71^{\dagger}$ & $<0.001^{\ddagger}$ \\
\hline Beck Depression Inventory & $34.41(10.86)$ & $26.70(10.40)$ & $-3.40^{\dagger}$ & $0.001^{\ddagger}$ \\
\hline Beck Anxiety Inventory & $31.14(12.12)$ & $23.52(14.30)$ & $-2.68^{\dagger}$ & $0.009^{\ddagger}$ \\
\hline Rumination Response Scale & $61.98(11.87)$ & $50.65(16.50)$ & $-3.67^{\dagger}$ & $<0.001^{\ddagger}$ \\
\hline
\end{tabular}

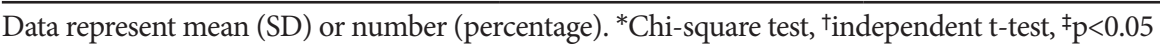


no significant interactions among time $\times$ treatment $\left(\mathrm{F}_{1.52,123.44}=\right.$ 2.03, $\left.\mathrm{p}=0.147, \eta^{2}=0.024\right)$ and time $\times$ treatment $\times$ atypicality $\left(\mathrm{F}_{1.52,123.44}=0.27, \mathrm{p}=0.704, \eta^{2}=0.003\right)$ for HAM- $\mathrm{D}_{17}$ total score. There were also no statistically significant interactions for the HAM-A, BDI, BAI, or RRS, nor any differences in cognitive function tests (digit span, verbal fluency, TMT-A, and TMT-B) at week 8 between the groups.

\section{Cognitive function changes}

For all participants, the independent t-test indicated that changes on cognitive function tests from baseline to endpoint were not significantly different between groups; however, in MDD patients without atypical features, we found a significant change in digit span score from baseline to endpoint between the groups $(t=-2.41, \mathrm{p}=0.023)$, but not in word fluency, TMT-A, or TMT-B (Figure 1). Participants with atypical MDD did not show any differences from baseline to endpoint.

Further, paired t-test were conducted between weeks 0 and 8 in the participants with MDD without atypical features for the cognitive assessments (Table 3). Digit span was significant-

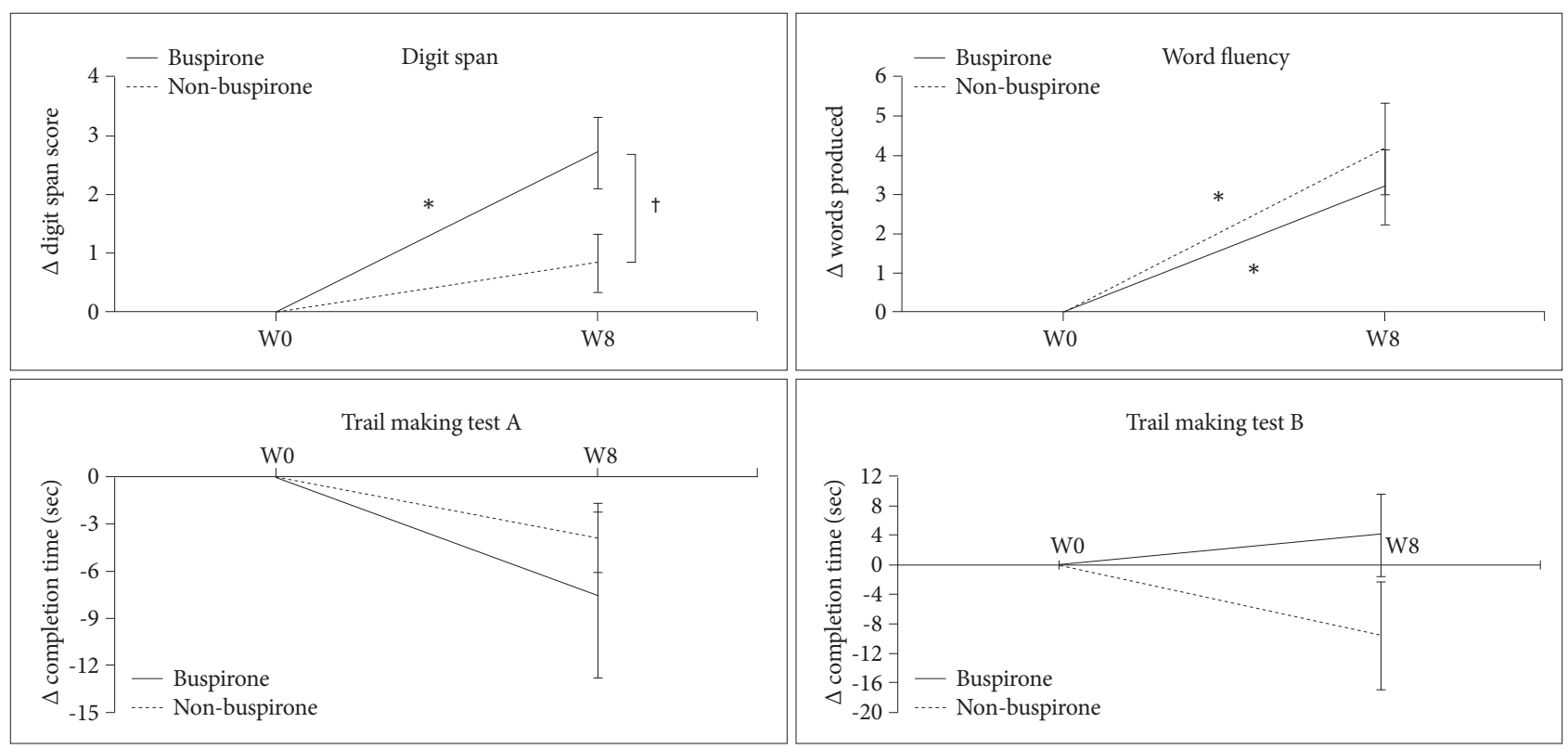

Figure 1. Mean changes on cognitive function tests in MDD patients without atypical features. Values are reported as mean change \pm standard error of the mean. ${ }^{*} p<0.05$, baseline versus week $8,{ }^{\dagger} p<0.05$ buspirone augmentation versus non-buspirone group. MDD: major depressive disorder.

Table 3. Mean scores of digit span, word fluency, trail making test A, and trail making test B from baseline to week 8 in the participants with major depressive disorder without atypical features

\begin{tabular}{|c|c|c|c|c|c|c|}
\hline & \multicolumn{2}{|c|}{ Buspirone augmentation $(\mathrm{N}=22)$} & \multirow{2}{*}{$\mathrm{p}$ of paired $\mathrm{t}$ test } & \multicolumn{2}{|c|}{ Non-buspirone (N=19) } & \multirow{2}{*}{$\mathrm{p}$ of paired $\mathrm{t}$ test } \\
\hline & Mean (SD) & Mean (SD) change & & Mean (SD) & Mean (SD) change & \\
\hline \multicolumn{7}{|l|}{ Digit span } \\
\hline Baseline & $16.00(3.31)$ & & & $17.34(4.57)$ & & \\
\hline Week 8 & $18.714(3.17)$ & $2.71(2.27)$ & $0.001^{*}$ & $18.19(4.83)$ & $0.84(1.98)$ & 0.109 \\
\hline \multicolumn{7}{|c|}{ Word fluency } \\
\hline Baseline & $15.93(3.52)$ & & & $19.06(6.97)$ & & \\
\hline Week 8 & $19.14(5.16)$ & $3.21(3.56)$ & $0.005^{*}$ & $23.24(6.56)$ & $4.18(4.85)$ & $0.003^{*}$ \\
\hline \multicolumn{7}{|c|}{ Trail making test $\mathrm{A}$} \\
\hline Baseline & $40.43(24.51)$ & & & $43.24(20.50)$ & & \\
\hline Week 8 & $32.93(12.83)$ & $-7.50(19.74)$ & 0.179 & $38.29(19.62)$ & $-3.94(9.09)$ & 0.093 \\
\hline \multicolumn{7}{|c|}{ Trail making test B } \\
\hline Baseline & $69.22(28.82)$ & & & $110.31(75.32)$ & & \\
\hline Week 8 & $73.22(30.30)$ & $4.00(16.84)$ & 0.496 & $100.81(68.79)$ & $-9.50(28.91)$ & 0.208 \\
\hline
\end{tabular}

Data represent mean [standard deviation $(\mathrm{SD})] .{ }^{*} \mathrm{p}<0.05$ 
ly improved in the buspirone augmentation group $(\Delta=2.71 \pm$ 2.27, $\mathrm{t}=-4.48, \mathrm{p}=0.003)$, while it was not improved in nonbuspirone group $(\Delta=0.84 \pm 1.98, \mathrm{t}=-1.70, \mathrm{p}=0.109)$. Word fluency was significantly improved both in the buspirone augmentation $(\Delta=3.21 \pm 3.56, \mathrm{t}=-3.38, \mathrm{p}=0.005)$ and nonbuspirone groups $(\Delta=4.18 \pm 4.85, \mathrm{t}=-3.55, \mathrm{p}=0.003)$. TMT-A and TMT-B did not show any significant improvements.

\section{DISCUSSION}

To our knowledge, our present study is the first to assess the effects of the buspirone augmentation of escitalopram on psychological symptoms and cognitive function. Firstly, buspirone augmentation did not show any statistically significant superiority to only escitalopram in all efficacy measurements and cognitive function tests. Secondly, digit span and word fluency tests, compared to TMT-A and TMT-B, showed significant improvements with antidepressant treatment in patients with depression without atypicality. Thirdly, in the participants with MDD without atypical features, the buspirone augmentation group demonstrated a significantly superior improvement on the digit span test compared with the nonbuspirone group.

Buspirone augmentation did not show any statistically significant superiority to the non-buspirone group in all efficacy measurements and cognitive function tests in our entire participants. To treat MDD, the benefits of buspirone are thought to be due to an increase in the activation of the postsynaptic 5-HT1A receptor in the presence of 5-HT1A autoreceptors that have already been desensitized by antidepressants; ${ }^{36,37}$ however, previous studies have rarely reported positive therapeutic effects of buspirone augmentation therapy in the treatment of non-treatment resistant MDD. A randomized, openlabel study in 120 non-resistant MDD patients showed no superior response rates in patients treated with fluoxetine alone versus fluoxetine coupled with buspirone. ${ }^{38}$

The digit span and word fluency tests, compared to TMT$\mathrm{A}$ and $\mathrm{B}$, showed significant improvements from antidepressant with or without buspirone in the MDD patients without atypical features. The results of which cognitive domains were improved by antidepressant trials in MDD patients have not been consistent in previous literature. ${ }^{39-41}$ The digit span and verbal fluency tests represent cognitive function, specifically in attention, working memory, and executive function, which have been reported to be impaired by $\mathrm{MDD}^{3,42}$; however, TMT$A$ and $B$ are not only a measure of executive function, but also processing speed. Previous studies have reported the improvement of TMT-B to be inconsistent in antidepressant trials in MDD patients. ${ }^{43-45}$

SSRIs and serotonin-norepinephrine reuptake inhibitors have been reported to improve working memory and executive function better than tricyclic antidepressants, ${ }^{46,47}$ and sertraline has been found to improve attention, working memory, and executive function better than fluoxetine ${ }^{48}$ Recently, vortioxetine, which acts on the multi-receptor of 5-HT, has been shown to improve attention, executive function, and working memory independently of its treatment effects on MDD symptoms, ${ }^{49}$ and improves cognitive function better than other antidepressants. ${ }^{41}$ Most of the studies of antidepressant augmentation with 'cognitive enhancers' (e.g., donepezil and galatamine) showed superior cognitive improvements compared to antidepressants alone. ${ }^{40}$ Our present results demonstrate the advantage of buspirone augmentation therapy for cognitive enhancement in MDD patients.

Although we were unable to confirm our initial hypothesis that buspirone would enhance cognition in all MDD patients, in the MDD participants without atypical features, the buspirone augmentation group showed significantly superior improvements in digit span compared to the non-buspirone group. Therefore, in the MDD patients without atypical features, antidepressant treatment improved attention, executive function, and working memory in addition to the therapeutic effects of antidepressant treatment on depressive symptoms of MDD. Moreover, in the MDD patients without atypical features, dysfunction of the HPA axis has been accepted as a characteristic biological finding ${ }^{20,50}$ and typically leads to reduced 5-HT1A receptor activity and hippocampal involvement. ${ }^{51,52}$ Therefore, it can be hypothesized that 5-HT1A agonists can restore hippocampal dysfunction by restoring 5-HT1A receptor function in depression without atypical features. In animal models of traumatic brain injury, treatment with buspirone attenuated spatial memory deficits. ${ }^{53,54}$ In this context in the present study, buspirone augmentation therapy may have provided additional cognitive improvements by recovering hippocampal and prefrontal-hippocampal connectivity through the restoration of hippocampal 5-HT1A function. There is little clinical evidence supporting buspirone as a cognitive enhancement pharmacotherapy in psychiatric illnesses, including MDD. In schizophrenia patients, buspirone augmentation therapy with antipsychotics only showed additional cognitive enhancing effects on various cognitive tests. ${ }^{16}$ The present study is the first that reveals improvement effects on cognition with buspirone in MDD, especially without atypical features subtype. Based on our findings, we suggest that, in the MDD patients without atypical features, buspirone may be effective in improving cognitive function.

It would be important to understand the clinical and biological differences between depression with atypcal features and depression without atypical features because atypical 
features influenced clinical outcome in this study. Atypicality of MDD is determined by symptoms such as mood reactivity, appetite, sleep, and psychomotor activity. ${ }^{18}$ The symptoms of MDD with atypical features include significant weight gain or increase in appetite, excessive sleep all through the day, and leaden paralysis. Otherwise, the MDD patients without atypical features show lack of mood reactivity, significant anorexia or weight loss, decreased sleep, and psychomotor retardation or agitation. Several biological aspects are known to differ according to atypicality of depression. A recent metaanalysis reported that the regulation of the HPA axis was different between depression with atypcal features and depression without atypical features. ${ }^{20}$ In the study, depression without atypical features showed hypercortisolism, and it was generally normal in depression with atypical features. In addition, inflammation appears to be significantly greater in patients with atypical depression, and depression with atypical features has a different proinflammatory cytokine pattern from depression without atypical features. ${ }^{55}$

\section{Limitations}

The present study was limited due to the small sample size and requires a greater sample size in future endeavors. Secondly, the present study was only 8 weeks, which may not have been sufficient time to see any significant cognitive improvements in patients with MDD. Thirdly, we could not rule out a possible placebo effect.

\section{Conclusion}

We did not determine buspirone augmentation of escitalopram to be a superior treatment compared to exclusively escitalopram for depressive symptoms in MDD patients; however, in the MDD participants without atypical features, digit span and word fluency tests were significantly improved by antidepressant treatment. In addition, buspirone augmentation treatment showed superior efficacy in improving digit span compared to non-buspirone treatment. Future studies are necessary to replicate our results, therefore confirming a subtype-dependent therapeutic effect of buspirone augmentation treatment on cognitive function in patients with MDD.

\section{Acknowledgments}

This study was supported by a grant from Boryung Pharmaceutical Co., Ltd., and partly supported by the Institute of Information \& communications Technology Planning \& Evaluation (IITP) grant funded by the Korea government (MSIT) (No. 2020-0-01376, Development of the multi-speaker conversational speech recognition technology).

\section{Conflicts of Interest}

The authors have no potential conflicts of interest to disclose.

\section{Author Contributions}

Conceptualization: Seung-Hwan Lee, Young-Hoon Ko, Se-Hoon Shim.
Protocol development: Seung-Hwan Lee, Young-Hoon Ko, Se-Hoon Shim, Kyoung-Sae Na, Sang-Woo Hahn. Intellectual comments and critics on the content: Se-Hoon Shim, Sang-Woo Hahn. Funding: Seung-Hwan Lee. Data acquisition: Seung-Hwan Lee, Young-Hoon Ko, Se-Hoon Shim, Ji Sun Kim, Kyoung-Sae Na, Sang-Woo Hahn. Formal analysis: Cheolmin Shin, Seung-Hwan Lee. Writing_original draft: Cheolmin Shin, Ji Sun Kim. Writing-review \& editing: Seung-Hwan Lee, Young-Hoon Ko.

\section{ORCID iDs}

Cheolmin Shin

Young-Hoon Ko

Se-Hoon Shim

Ji Sun Kim

Kyoung-Sae $\mathrm{Na}$

Sang-Woo Hahn

Seung-Hwan Lee

https://orcid.org/0000-0002-8232-2921

https://orcid.org/0000-0002-5352-2158

https://orcid.org/0000-0002-3137-6591

https://orcid.org/0000-0003-2472-4591

https://orcid.org/0000-0002-0148-9827

https://orcid.org/0000-0003-1662-5438

https://orcid.org/0000-0003-0305-3709

\section{REFERENCES}

1. Spijker J, Graaf R, Bijl RV, Beekman AT, Ormel J, Nolen WA. Functional disability and depression in the general population. Results from the Netherlands Mental Health Survey and Incidence Study (NEMESIS). Acta Psychiatr Scand 2004;110:208-214.

2. Russo M, Mahon K, Burdick KE. Measuring cognitive function in MDD: emerging assessment tools. Depress Anxiety 2015;32:262-269.

3. Zuckerman H, Pan Z, Park C, Brietzke E, Musial N, Shariq AS, et al. Recognition and treatment of cognitive dysfunction in major depressive disorder. Front Psychiatry 2018;9:655.

4. Rush AJ, Trivedi MH, Wisniewski SR, Nierenberg AA, Stewart JW, Warden $\mathrm{D}$, et al. Acute and longer-term outcomes in depressed outpatients requiring one or several treatment steps: a STAR ${ }^{\star} \mathrm{D}$ report. Am J Psychiatry 2006;163:1905-1917.

5. Nelson JC, Pikalov A, Berman RM. Augmentation treatment in major depressive disorder: focus on aripiprazole. Neuropsychiatr Dis Treat 2008;4:937-948.

6. Apter JT, Allen LA. Buspirone: future directions. J Clin Psychopharmacol 1999;19:86-93.

7. Lechin F, van der Dijs B, Jara H, Orozco B, Baez S, Benaim M, et al. Effects of buspirone on plasma neurotransmitters in healthy subjects. J Neural Transm (Vienna) 1998;105:561-573.

8. Fabre LF. Buspirone in the management of major depression: a placebo-controlled comparison. J Clin Psychiatry 1990;51 (Suppl):55-61.

9. Heiser JF, Wilcox CS. Serotonin 5-HT 1a receptor agonists as antidepressants. Cns Drugs 1998;10:343-353.

10. McAllister-Williams RH, Alhaj HA, Massey A, Pankiv J Reckermann U. Somatodendritic 5-hydroxytryptamine1A (5-HT1A) autoreceptor function in major depression as assessed using the shift in electroencephalographic frequency spectrum with buspirone. Psychol Med 2014;44:767777.

11. Depoortere R, Auclair AL, Bardin L, Colpaert FC, Vacher B, NewmanTancredi A. F15599, a preferential post-synaptic 5-HT1A receptor agonist: activity in models of cognition in comparison with reference 5-HT1A receptor agonists. Eur Neuropsychopharmacol 2010;20:641654 .

12. Micheau J, Van Marrewijk B. Stimulation of 5-HT1A receptors by systemic or medial septum injection induces anxiogenic-like effects and facilitates acquisition of a spatial discrimination task in mice. Prog Neuropsychopharmacol Biol Psychiatry 1999;23:1113-1133.

13. Givens BS, Olton DS. Cholinergic and GABAergic modulation of medial septal area: effect on working memory. Behav Neurosci 1990;104: 849-855.

14. Haleem DJ, Nawaz S, Salman T. Dose related effects of buspirone on pain, learning/memory and food intake. Regul Toxicol Pharmacol 2018;99: 182-190.

15. Sumiyoshi T, Matsui M, Nohara S, Yamashita I, Kurachi M, Sumiyoshi 
C, et al. Enhancement of cognitive performance in schizophrenia by addition of tandospirone to neuroleptic treatment. Am J Psychiatry 2001;158:1722-1725

16. Sumiyoshi T, Park S, Jayathilake K, Roy A, Ertugrul A, Meltzer HY. Effect of buspirone, a serotonin1A partial agonist, on cognitive function in schizophrenia: a randomized, double-blind, placebo-controlled study. Schizophr Res 2007;95:158-168.

17. Gili M, Roca M, Armengol S, Asensio D, Garcia-Campayo J, Parker G. Clinical patterns and treatment outcome in patients with melancholic, atypical and non-melancholic depressions. PLoS One 2012;7:e48200.

18. Singh T, Williams K. Atypical depression. Psychiatry (Edgmont) 2006; 3:33-39.

19. Anisman H, Ravindran AV, Griffiths J, Merali Z. Endocrine and cytokine correlates of major depression and dysthymia with typical or atypical features. Mol Psychiatry 1999;4:182-188.

20. Juruena MF, Bocharova M, Agustini B, Young AH. Atypical depression and non-atypical depression: is HPA axis function a biomarker? A systematic review. J Affect Disord 2018;233:45-67.

21. Pizzagalli DA, Oakes TR, Fox AS, Chung MK, Larson CL, Abercrombie HC, et al. Functional but not structural subgenual prefrontal cortex abnormalities in melancholia. Mol Psychiatry 2004;9:325, 393-405.

22. Exner C, Lange C, Irle E. Impaired implicit learning and reduced presupplementary motor cortex size in early-onset major depression with melancholic features. J Affect Disord 2009;119:156-162.

23. Austin MP, Mitchell P, Wilhelm K, Parker G, Hickie I, Brodaty H, et al. Cognitive function in depression: a distinct pattern of frontal impairment in melancholia? Psychol Med 1999;29:73-85.

24. Brown WA. Treatment response in melancholia. Acta Psychiatr Scand Suppl 2007:125-129.

25. Hamilton M. A rating scale for depression. J Neurol Neurosurg Psychiatry 1960;23:56-62.

26. Stewart JW, McGrath PJ, Rabkin JG, Quitkin FM. Atypical depression. A valid clinical entity? Psychiatr Clin North Am 1993;16:479-495.

27. Hamilton M. The assessment of anxiety states by rating. $\mathrm{Br} J$ Med Psychol 1959;32:50-55.

28. Beck AT, Ward CH, Mendelson M, Mock J, Erbaugh J. An inventory for measuring depression. Arch Gen Psychiatry 1961;4:561-571.

29. Beck AT, Epstein N, Brown G, Steer RA. An inventory for measuring clinical anxiety: psychometric properties. J Consult Clin Psychol 1988; 56:893-897.

30. Guy W. ECDEU Assessment manual for psychopharmacology. US Department of Health, and Welfare 1976:534-537.

31. Treynor W, Gonzalez R, Nolen-Hoeksema S. Rumination reconsidered: A psychometric analysis. Cogn Ther Res 2003;27:247-259.

32. Wechsler D. Wechsler Adult Intelligence Scale-Fourth Edition (WAISIV). San Antonio, TX: NCS Pearson 2008;22:498.

33. Morris JC, Heyman A, Mohs RC, Hughes JP, van Belle G, Fillenbaum G, et al. The Consortium to Establish a Registry for Alzheimer's Disease (CERAD). Part I. Clinical and neuropsychological assessment of Alzheimer's disease. Neurology 1989;39:1159-1165.

34. Bowie CR, Harvey PD. Administration and interpretation of the Trail Making Test. Nat Protoc 2006;1:2277-2281.

35. Fitzmaurice GM, Laird NM, Ware JH. Applied Longitudinal Analysis. New York: John Wiley \& Sons; 2012.

36. Appelberg BG, Syvalahti EK, Koskinen TE, Mehtonen OP, Muhonen TT Naukkarinen HH. Patients with severe depression may benefit from buspirone augmentation of selective serotonin reuptake inhibitors: results from a placebo-controlled, randomized, double-blind, placebo wash-in study. J Clin Psychiatry 2001;62:448-452.

37. Landen M, Bjorling G, Agren H, Fahlen T. A randomized, double-blind, placebo-controlled trial of buspirone in combination with an SSRI in patients with treatment-refractory depression. J Clin Psychiatry 1998;
59:664-668.

38. Onder E, Tural U. Faster response in depressive patients treated with fluoxetine alone than in combination with buspirone. J Affect Disord 2003;76:223-227.

39. Wagner S, Doering B, Helmreich I, Lieb K, Tadic A. A meta-analysis of executive dysfunctions in unipolar major depressive disorder without psychotic symptoms and their changes during antidepressant treatment. Acta Psychiatr Scand 2012;125:281-292.

40. Keefe RS, McClintock SM, Roth RM, Doraiswamy PM, Tiger S, Madhoo M. Cognitive effects of pharmacotherapy for major depressive disorder: a systematic review. J Clin Psychiatry 2014;75:864-876.

41. Rosenblat JD, Kakar R, McIntyre RS. The cognitive effects of antidepressants in major depressive disorder: a systematic review and meta-analysis of randomized clinical trials. Int J Neuropsychopharmacol 2015;19: pyv082.

42. Murrough JW, Iacoviello B, Neumeister A, Charney DS, Iosifescu DV. Cognitive dysfunction in depression: neurocircuitry and new therapeutic strategies. Neurobiol Learn Mem 2011;96:553-563.

43. Hoffman BM, Blumenthal JA, Babyak MA, Smith PJ, Rogers SD, Doraiswamy PM, et al. Exercise fails to improve neurocognition in depressed middle-aged and older adults. Med Sci Sports Exerc 2008;40: 1344-1352.

44. Robinson M, Oakes TM, Raskin J, Liu P, Shoemaker S, Nelson JC. Acute and long-term treatment of late-life major depressive disorder: duloxetine versus placebo. Am J Geriatr Psychiatry 2014;22:34-45.

45. Rocca P, Calvarese P, Faggiano F, Marchiaro L, Mathis F, Rivoira E, et al. Citalopram versus sertraline in late-life nonmajor clinically significant depression: a 1-year follow-up clinical trial. J Clin Psychiatry 2005;66: 360-369.

46. Bondareff W, Alpert M, Friedhoff AJ, Richter EM, Clary CM, Batzar E. Comparison of sertraline and nortriptyline in the treatment of major depressive disorder in late life. Am J Psychiatry 2000;157:729-736.

47. Levkovitz Y, Caftori R, Avital A, Richter-Levin G. The SSRIs drug Fluoxetine, but not the noradrenergic tricyclic drug Desipramine, improves memory performance during acute major depression. Brain Res Bull 2002;58:345-350.

48. Finkel SI, Richter EM, Clary CM, Batzar E. Comparative efficacy of sertraline vs. fluoxetine in patients age 70 or over with major depression. Am J Geriatr Psychiatry 1999;7:221-227.

49. McIntyre RS, Lophaven S, Olsen CK. A randomized, double-blind, placebo-controlled study of vortioxetine on cognitive function in depressed adults. Int J Neuropsychopharmacol 2014;17:1557-1567.

50. Lamers F, Vogelzangs N, Merikangas KR, de Jonge P, Beekman AT, Penninx BW. Evidence for a differential role of HPA-axis function, inflammation and metabolic syndrome in melancholic versus atypical depression. Mol Psychiatry 2013;18:692-699.

51. Savitz J, Lucki I, Drevets WC. 5-HT(1A) receptor function in major depressive disorder. Prog Neurobiol 2009;88:17-31.

52. Schmidt HD, Duman RS. The role of neurotrophic factors in adult hippocampal neurogenesis, antidepressant treatments and animal models of depressive-like behavior. Behav Pharmacol 2007;18:391-418.

53. Olsen AS, Sozda CN, Cheng JP, Hoffman AN, Kline AE. Traumatic brain injury-induced cognitive and histological deficits are attenuated by delayed and chronic treatment with the 5-HT1A-receptor agonist buspirone. J Neurotrauma 2012;29:1898-1907.

54. Monaco CM, Gebhardt KM, Chlebowski SM, Shaw KE, Cheng JP, Henchir JJ, et al. A combined therapeutic regimen of buspirone and environmental enrichment is more efficacious than either alone in enhancing spatial learning in brain-injured pediatric rats. J Neurotrauma 2014;31:1934-1941.

55. Lojko D, Rybakowski JK. Atypical depression: current perspectives. Neuropsychiatr Dis Treat 2017;13:2447-2456. 